\title{
Una Vision del Arbitraje
}

\author{
Mitxel Unzueta \\ Presidente del Tribunal Arbitral de la Cámara de Comercio de Bilbao
}

\section{Consideraciones generales}

La finalidad de esta exposición es la de facilitar una visión didáctica del sistema de arbitraje, poco conocido hoy en día, en muchos sectores de las actividades, especialmente el económico.

La Institución Arbitral es muy antigua. Griegos y romanos la incorporaron a sus sistemas legales. Con el tiempo, algunas concepciones doctrinales vieron el arbitraje con poca simpatía; consideraban que la potestad de resolver conflictos era una atribución exclusiva del Estado.

Esta cuestión supera estas notas.

Hay una razón histórica que explica este aún limitado desarrollo de la cultura arbitral. La Ley de 1.953, más que facilitar el arbitraje, lo dificultaba, lo que provocó que, mientras en otros países de Europa el arbitraje, sobre todo internacional, fue expansionándose, aquí se convirtió en una institución jurídica casi desconocida. La situación empezó a cambiar con la Ley 36/1988, de 5 de diciembre, de Arbitraje, que implantó una regulación que nos aproximaba a los demás países de la Unión Europea.

Esta Ley ha quedado derogada por la vigente, que es la Ley 60/2003, de 23 de diciembre, de Arbitraje.

Está inspirada en los principios de la llamada Ley Modelo, elaborada por la Comisión de las Naciones Unidas para el Derecho Mercantil Internacional (es conocida con la referencia Ley Modelo de CNUDMI/ UNCITRAL).

Esta Ley es consecuencia del mandato contenido en la Resolución 40/72 de la Asamblea General de las Naciones Unidas. La Ley 
Modelo fue un compromiso equilibrado, que ensambló las tradiciones jurídico-arbitrales sajonas y las europeo-continentales.

Se trata de una norma que permite un desarrollo del arbitraje, otorgando una amplia libertad a las partes para regular la forma de tramitar el arbitraje, determinación del derecho aplicable y elección de árbitros.

Para cerrar este capítulo, anotaré dos ideas claves:

—El arbitraje es un sistema alternativo para resolver conflictos. El arbitraje sustituye al pleito.

- La Sentencia dictada por un árbitro es tan ejecutable como una Sentencia judicial. Si una Sentencia arbitral no se cumple voluntariamente, puede solicitarse del Juzgado la ejecución forzosa de la misma.

\section{Interés del arbitraje}

Pueden señalarse varias razones que avalan la utilización del arbitraje:

— La operatividad. Frente a la complejidad de los procedimientos judiciales, el arbitraje es mucho más sencillo y adaptable a cada caso. No existe la rigidez formal para la articulación de escritos o presentación de pruebas; los plazos se pactan.

Evidentemente, hay que respetar los principios de igualdad de trato a las partes para defender sus derechos; de contradicción, para que todas puedan conocer las alegaciones y pruebas contrarias y de audiencia, para ser oídas. Las decisiones tienen que estar motivadas (arts. ${ }^{\circ} 24$ y 37.4).

A pesar de esta flexibilidad, se llega a la Sentencia en plazos infinitamente más breves que en los Tribunales.

- Confidencialidad. Las actuaciones arbitrales son reservadas (art. ${ }^{\circ}$ 242), lo que garantiza que el conocimiento de determinados datos (informaciones técnicas comerciales) queden limitados al árbitro y las partes.

-Facilita el acercamiento de las partes, algo que no es frecuente en el sistema judicial.

- A pesar de que hay que abonar los honorarios del árbitro, no tiene por qué ser más caro que el pleito judicial. 
- Pueden pactarse las cuantías de los honorarios del árbitro, Letrados, etc.

- Es el único sistema que da respuesta a la necesidad de resolver los conflictos en una economía globalizada. El arbitraje no tiene fronteras, permite elegir el derecho aplicable, los árbitros pueden actuar en cualquier lugar y la efectividad de sus decisiones está garantizada en los países que han suscrito el Convenio de New York para el reconocimiento y ejecución de las Sentencias arbitrales extranjeras (10.06.1958. España lo ratificó el 12.05.1977).

No hay que olvidar que el arbitraje se adapta mejor a las disputas de carácter mercantil que a otras de tipo personal. También que el litigante temerario o de mala fe, generalmente, prefiere el pleito judicial.

\section{Arbitraje y mediación. Arbitrajes especiales}

Hay que distinguir lo que es arbitraje, en sentido estricto, de otras instituciones que tratan de resolver los conflictos; tal es el caso de la mediación.

A grandes rasgos, hay que tener en cuenta que la resolución arbitral es como una decisión judicial, mientras que la mediación, o conduce a un acuerdo, cuyo valor depende de que lo asuman las partes, o no genera ningún resultado. En la mediación no hay un tercero que impone su decisión. Pero, en todo caso, el acuerdo alcanzado ante un mediador no se puede ejecutar como una Sentencia judicial o arbitral.

Existe una gran variedad de entidades que practican sistemas de mediación, con métodos propios para el «Reglamento alternativo de diferencias»(ADR). (Mini-trial; Comités para el Reglamento de diferencias; partenariado; expertizajes técnicos, etc.).

Ahora hablamos sólo del arbitraje.

Algunas Leyes prevén sistemas arbitrales específicos, como es el caso de la normativa sobre Consumidores, el Transporte Terrestre, Seguros, Propiedad Intelectual, Protección Jurídica de Diseño Industrial, Marcas, Deporte y Minusválidos.

Pero en todos estos sistemas arbitrales, la Ley que comentamos, es de carácter supletorio. 


\section{¿Qué cuestiones son susceptibles de ser resueltas a través del arbitraje?}

En principio, todas las cuestiones que se refieran a materias que están en la libre disposición de las partes, conforme a Derecho. El art. ${ }^{\circ} 2$ es de una gran amplitud.

Durante años, la jurisprudencia fue muy contraria a la aplicación del arbitraje en los conflictos surgidos en el seno de las sociedades, bien entre socios y órganos sociales, o entre socios. A partir de la Sentencia de la Sala 1. ${ }^{\text {a }}$ del Tribunal Supremo, de fecha 18-04-1998 y la Resolución de la D. General de Registros y Notariado del 19-02-1998, este criterio ha evolucionado, admitiendo la aplicación del arbitraje a esta clase de conflictos, incluidos los relativos a la impugnación de acuerdos sociales.

Están excluidos los arbitrajes en materia laboral, limitación que no se da en otros países.

\section{¿Cómo se accede al arbitraje?}

Así como para acceder a los Tribunales de Justicia basta con tener la consideración de persona capaz, para acudir al arbitraje se requiere, además, un requisito específico: la existencia de un Convenio Arbitral. Si esta cláusula no existe, en principio, hasta que no se pacte, no se puede someter la controversia a arbitraje.

El Convenio arbitral es un acuerdo en virtud del cual las partes acuerdan someter a arbitraje la solución de los conflictos que hayan surgido o puedan surgir en torno a una determinada relación jurídica, contractual o no contractual.

Se da libertad de forma al contenido de la cláusula, siendo suficiente que queden identificadas las personas o entidades que adopten la cláusula arbitral, su decisión de someter a arbitraje las controversias que puedan producirse y una determinación suficiente para identificar la relación contractual. Salvadas estas exigencias, la cláusula o convenio puede ser sencilla o compleja, según la naturaleza de la relación; no existe una fórmula sacramental. Hay cláusulas estándar, que ofrecen los Centros de Arbitraje, pero no necesariamente deben ser así. Su utilización no pasa de ser una comodidad. 
Como ejemplo, se transcriben las que recomienda la Corte de Arbitraje de la Cámara de Comercio de Bilbao.

Cláusula Arbitral recomendada:

Las partes acuerdan que todo litigio o discrepancia que se derive de esta relación jurídica se resolverá definitivamente ante la Corte de Arbitraje de la Cámara de Comercio, Industria y Navegación de Bilbao, a la que encomiendan la administración del arbitraje y la designación del Árbitro(s), según su Reglamento y Estatutos.

\section{Cláusula Arbitral para Sociedades:}

Todas las cuestiones societarias litigiosas que se susciten entre la Sociedad y sus administradores o socios, o entre aquéllos y éstos, o entre estos últimos, se someten al arbitraje de la Corte de Arbitraje de la Cámara de Comercio, Industria y Navegación de Bilbao, a la que se le encomienda, de acuerdo con su Reglamento, la administración del arbitraje y la designación de los Árbitros, y cuyo laudo será de obligado cumplimiento.

Se exceptúan de este arbitraje las cuestiones sobre las que las partes no puedan válidamente disponer, o aquéllas respecto de las que la Ley determine la exclusiva competencia de una determinada jurisdicción.

Es necesario que el Convenio conste por escrito, pero no que esté en el mismo documento del que surge la relación jurídica. Puede resultar de un cruce de cartas, o de un soporte electrónico; o en un contrato de adhesión, y referirse a una o varias relaciones jurídicas (art. ${ }^{\circ}$ ).

Puede pactarse cuando se inicia la relación, o en el curso de ésta o cuando surge el conflicto.

Casos especiales son los del art. ${ }^{\circ} 10$ (cláusula de arbitraje en una disposición testamentaria) y el art. $^{\circ} 9-5^{\circ}$ (Convenio de Arbitraje a través de escritos judiciales).

\section{Arbitrajes internos y arbitrajes internacionales}

La Ley considera que un arbitraje tiene carácter internacional si concurre alguna de estas circunstancias: 
- Si las partes tienen sus domicilios en Estados diferentes.

- Que el lugar del arbitraje, el del cumplimiento de una parte sustancial de las obligaciones resultantes de la relación jurídica debatida o el lugar con el que ésta tenga una relación más estrecha, esté fuera del Estado en que las partes tengan su domicilio.

- Que la relación jurídica de la que dimane la controversia afecte a intereses del comercio internacional (art. ${ }^{\circ} 3$ ).

Si no es así, el arbitraje sería interno.

Ahora bien, esta distinción tiene una importancia relativa, ya que la Ley regula ambas clases de arbitraje de una manera unitaria (solamente en los arts. 3 y 46 aparecen especificidades en cuanto a plazos).

Para exigir judicialmente la ejecución de un laudo, tiene importancia el lugar en el que se dicta la Sentencia arbitral.

Si el laudo arbitral se dicta dentro del territorio del Estado, sea interno o internacional el arbitraje, aquél se ejecuta con sólo presentarlo en el Juzgado.

Por contra, si el lugar donde se pronuncia la Sentencia es un país extranjero, para pedir la ejecución es preciso pasar por el trámite del execuatur (dicho coloquialmente, equivale a su homologación) (art. $\left.{ }^{\circ} 46\right)$.

A este respecto, hay que tener en cuenta el citado Convenio de New York (en algún caso puede ser de aplicación otro de los Convenios existentes) y lo previsto en la L.E. Civil.

\section{Arbitraje de derecho o de equidad}

La Ley permite que el árbitro sentencie conforme a Derecho, o según los principios de la equidad. Salvo que las partes decidan que sea de equidad, la Ley presupone que es de derecho (art. ${ }^{\circ} 34$ ).

Sobre este punto hay que recordar:

-Que si el arbitraje es de derecho, el árbitro debe ser un «Abogado en ejercicio» (art. ${ }^{\circ} 15$ ). Sin embargo, las partes pueden pactar que el árbitro tenga otra titulación o competencia (v.g. un arquitecto, un experto contable, etc.). 
—Que, en principio, las partes pueden pactar cuál sea el derecho aplicable. Hay que tener en cuenta que existen limitaciones que impiden que determinados preceptos o instituciones se apliquen dentro del Estado (ejemplo clásico sería el de la pretensión del reconocimiento de una situación de poligamia en una disputa de intereses familiares).

- Que el concepto de equidad no tiene el mismo sentido en todos los sistemas jurídicos, por lo que en un arbitraje internacional ha de tenerse cuidado en la concreción del concepto (principios de la lex mercatoria).

\section{Administración del arbitraje}

Es un aspecto importante en la gestión del arbitraje (art. ${ }^{\circ} 14$ ). Puede encomendarse la administración del arbitraje a las Corporaciones de derecho público, Asociaciones e Instituciones que menciona el art. $^{\circ} 14$ de la Ley. Su misión fundamental es apoyar la realización del arbitraje, de acuerdo con un Reglamento que es específico de cada Centro, si bien todos son similares. El Centro internacional más conocido, es la C.C.I. de París.

Si la administración no se encomienda a una de estas entidades, las partes tienen que adoptar acuerdos específicos para el desarrollo del arbitraje. Completando lo que establece la Ley. Se trata de los arbitrajes «ad hoc».

En general, lo más interesante es pactar la administración del arbitraje. El apoyo logístico que prestan estas entidades es muy importante.

\section{Nombramiento de árbitros}

La clave fundamental para conseguir un arbitraje de calidad radica en la elección de un buen árbitro.

Hemos visto que en los arbitrajes de derecho, en principio, el árbitro debe ser un Abogado en ejercicio. Por contra, en los arbitrajes de equidad, puede serlo cualquier persona natural.

El número de árbitros debe ser impar. Lo más habitual es que se nombre un solo árbitro y, de formarse un colegio, éste lo componen tres. 
Para el nombramiento, hay tres procedimientos: en primer lugar, está el acuerdo de las partes. Si éste no se consigue y el arbitraje está siendo administrado, la designación se efectuará aplicando lo que diga el Reglamento de la Institución administradora.

Por ultimo, en los arbitrajes ad hoc, a falta de acuerdo, es la decisión del Juez la que nombra el árbitro, en la forma prevista en el art. $^{\circ} 15$ de la Ley.

Las cuatro calidades fundamentales que deben reunir los árbitros son: competencia profesional, experiencia en relación a los temas que se someten a su decisión, imparcialidad e independencia.

El árbitro debe aceptar la nominación. Frecuentemente, se le pide que firme un compromiso declarando no tener relaciones con las partes y actuar con imparcialidad, independencia y confidencialidad.

La Ley establece un procedimiento para la recusación de los árbitros, si hay lugar a ello y, así mismo, para su sustitución, en los casos que también están previstos en la Ley.

La responsabilidad del árbitro está regulada en el art. ${ }^{\circ} 21$.

El árbitro tiene amplias facultades para ordenar el procedimiento arbitral y, en concreto, para:

- Decidir sobre su propia competencia.

- Resolver los incidentes que se produzcan en el curso del arbitraje.

- Decidir en cuanto al fondo del asunto.

- Pedir el auxilio judicial, en los casos en que sea oportuno.

- Adoptar medidas cautelares.

- Nombrar Peritos.

\section{Procedimiento arbitral}

Es extraordinariamente sencillo y flexible. La regla fundamental es que el procedimiento se desarrolla conforme a lo que pacten las partes $y$, a falta de pacto, por el Reglamento de la Institución que administre el arbitraje.

En términos generales, el procedimiento suele tener tres fases. Una primera fase, destinada a la formulación de la demanda y la 
contestación, con la reconvención si procede. Una segunda fase, destinada a proponer y practicar pruebas. La tercera parte, es la de conclusiones.

Para la práctica de las pruebas, las entidades que administran arbitrajes suelen facilitar a las partes los locales adecuados y también sistemas de grabación de las manifestaciones de las partes, testigos y peritos.

\section{Auxilio judicial}

Como hemos visto, el árbitro tiene facultades de decidir sobre una serie de cuestiones, pero no tiene potestades coactivas en el caso de que alguien se negase a cumplir lo mandado. Para estos casos, la Ley establece la posibilidad de que el árbitro solicite el auxilio judicial.

Supuestos específicos de auxilio judicial son:

- El nombramiento de árbitros, si las partes no se ponen de acuerdo en los arbitrajes ad hoc (art. $\left.{ }^{\circ} 15\right)$.

- Apoyo a la práctica de pruebas, como es el caso de comparecencia de testigos, obtención de documentos, etc. (art. ${ }^{\circ} 33$ ).

-Ejecución forzosa de medidas cautelares o de la Sentencia arbitral.

\section{Finalización del arbitraje}

En principio, los arbitrajes terminan mediante la Sentencia o laudo, emitido por el árbitro.

Si el árbitro es un Tribunal colegiado, la decisión se adopta por mayoría, y si ésta no se consigue, será su Presidente quien decida.

La Sentencia arbitral debe ser emitida dentro del plazo establecido por las partes y, en otro caso, en el plazo máximo de seis meses. Las partes pueden acordar prórroga del plazo.

En el arbitraje, el laudo debe expresar el lugar y fecha en que se emite y estar firmado. Debe estar motivado.

El arbitraje termina así mismo por el desistimiento de la parte actora, así como cuando se hace imposible su continuación o ésta resul- 
ta innecesaria, teniendo en cuenta una posterior evolución de las relaciones entre partes.

Si las partes llegan a un acuerdo durante el arbitraje, pueden pedir al árbitro que en su Sentencia arbitral se limite a recoger este acuerdo.

El art. 39 establece los plazos y la forma en que las partes pueden solicitar al árbitro la corrección de errores, la aclaración de extremos dudosos o que complemente el laudo si ha omitido resolver sobre algún punto controvertido.

\section{Las costas}

Generalmente el árbitro tiene potestad para imponer las costas a una de las partes o distribuirlas entre todas. Sobre este punto hay que estar a lo que diga el Reglamento de la Institución arbitral o a lo que hubieren pactado las partes.

\section{Anulación del laudo}

Contra la decisión del árbitro no cabe un recurso de apelación en el sentido tradicional de la Ley de Enjuiciamiento Civil.

Sí es posible ejercitar ante los Tribunales de justicia una acción de anulación si se da alguno de los supuestos previstos en el art. ${ }^{\circ} 41$ de la Ley. El procedimiento para solicitar esta anulación aparece en el art. ${ }^{\circ} 42$.

Los Tribunales de justicia son muy estrictos en la interpretación de los motivos de anulación, de forma que generalmente fracasan algunas acciones de anulación que se enfocan como una revisión de la decisión arbitral, a través de una nueva valoración de pruebas, etc.

Las precedentes notas no pretenden más que dar una visión general del arbitraje, por ello se han omitido las referencias a cuestiones de detalle o aspectos particulares cuya solución el estudioso de estos temas no tendrá dificultad en encontrar en el texto legal. 